\title{
An Anticipatory Circuit Modification That Modifies Subsequent Task Switching
}

\author{
Yanqing Wang, Michael A. Barry, Monica Cambi, ${ }^{\circledR}$ Klaudiusz R. Weiss, and ${ }^{\circledR}$ Elizabeth C. Cropper \\ Department of Neuroscience and Friedman Brain Institute, Icahn School of Medicine at Mount Sinai, New York, New York 10029
}

Modulators are generally expected to establish a network configuration that is appropriate for the current circumstances. We characterize a situation where the opposite is apparently observed. A network effect of a peptide modulator is counterproductive in that it tends to impede rather than promote the creation of the configuration that is appropriate when the modulator is released. This raises a question: why does release occur? We present data that strongly suggest that it impacts task switching. Our experiments were conducted in an Aplysia feeding network that generates egestive and ingestive motor programs. Initial experiments focused on egestive activity and the neuron B8. As activity becomes egestive, there is an increase in synaptic drive to B8 and its firing frequency increases (Wang et al., 2019). We show that, as this occurs, there is also a persistent current that develops in B8 that is outward rather than inward. Dynamic clamp introduction of this current decreases excitability. When there is an egestive-ingestive task switch in Aplysia, negative biasing is observed (i.e., a bout of egestive activity has a negative impact on a subsequent attempt to initiate an ingestive response) (Proekt et al., 2004). Using an in vitro analog of negative biasing, we demonstrate that the outward current that develops during egestive priming plays an important role in establishing this phenomenon. Our data suggest that, although the outward current induced as activity becomes egestive is counterproductive at the time, it plays an anticipatory role in that it subsequently impacts task switching.

Key words: Aplysia; dynamic clamp; feeding; mollusc; outward current

Significance Statement

In this study, we identify a peptide-induced circuit modification (induction of an outward current) that does not immediately promote the establishment of a behaviorally appropriate network configuration. We ask why this might occur, and present data that strongly suggest that it plays an important role during task switching. Specifically, our data suggest that the outward current we characterize plays a role in the negative biasing that is seen in the mollusc Aplysia when there is a transition from egestive to ingestive activity. It is possible that the mechanism that we describe operates in other species. A negative effect of egestion on subsequent ingestion is observed throughout the animal kingdom.

\section{Introduction}

It is widely recognized that a modulator, or group of modulators, can be released under a particular set of circumstances and can modify circuit parameters so that an appropriate network configuration is assumed. For example, a starved fly releases short NPF (sNPF), which facilitates neurotransmitter release from olfactory neurons and stimulates food search. In contrast, when flies feed, insulin-related peptides

Received Aug. 16, 2020; revised Jan. 3, 2021; accepted Jan. 14, 2021.

Author contributions: E.C.C., Y.W., M.A.B., and K.R.W. designed research; E.C.C. wrote the first draft of the paper; E.C.C., Y.W., M.A.B., and K.R.W. edited the paper; E.C.C. wrote the paper; Y.W., M.A.B., and M.C. performed research; Y.W. and M.A.B. analyzed data.

The authors declare no competing financial interests.

This work was supported by the National Institutes of Health Grants NS066587 and NS070583.

Correspondence should be addressed to Elizabeth C. Cropper at elizabeth.cropper@gmail.com.

https://doi.org/10.1523/JNEUROSCI.2427-20.2021

Copyright $\odot 2021$ the authors suppress the transcription of the sNPF receptor (Root et al., 2011). Our research demonstrates that effects of a modulator can be apparently "counterproductive" in that they impede rather than promote the creation of a behaviorally appropriate network configuration. This leads to the obvious question: why is the modulator released? We test a hypothesis suggested by the fact that the modulatory effects we study persist and outlast the phase of behavior in which release occurs. This suggests a potential "anticipatory" role in task switching. We present data that support this idea.

Our experiments were conducted in the feeding network of the mollusc, Aplysia. This network controls movements of the radula, the organ that is used to grasp food and move it into the buccal cavity (Krings et al., 2019). Feeding movements in Aplysia can be either egestive or ingestive (Kupfermann, 1974). When movements are egestive, the radula closes as it protracts, which pushes food (or an object) out of the buccal cavity (Morton and 
Chiel, 1993a,b). When movements are ingestive the radula closes as it retracts pulling food in.

Egestive and ingestive movements are both central pattern generator (CPG) mediated (Cropper et al., 2017). In vitro, egestive activity can be triggered by activation of an "egestive" input to the feeding CPG, the esophageal nerve (EN) (e.g., Proekt et al., 2004; Friedman et al., 2009; Dacks and Weiss, 2013; Siniscalchi et al., 2016). Ingestive activity can be triggered by activation of an "ingestive" input, the command-like neuron CBI-2 (Rosen et al., 1991; Church and Lloyd, 1994; Sanchez and Kirk, 2001; Morgan et al., 2002). However, if a single cycle of motor activity is triggered in a previously quiescent preparation an "intermediate" cycle of activity is most commonly generated (Proekt et al., 2004). Motor neurons fire at relatively low frequencies and antagonistic motor neurons are coactive. When multiple cycles of activity are generated, the situation changes. For example, with repeated stimulation of the EN, activity becomes more and more egestive (Proekt et al., 2004; Friedman et al., 2009, 2015).

As activity becomes egestive, the $\mathrm{B} 8$ neurons receive increased synaptic input and their firing frequency increases (Proekt et al., 2004; Friedman et al., 2009; Wang et al., 2019). In this study, we demonstrate that, as activity becomes egestive, a persistent current also develops in B8 that is outward rather than inward. Dynamic clamp introduction of the current decreases excitability. Thus, induction of the outward current is counterproductive in that it tends to oppose the firing frequency increase that results from the increase in synaptic drive.

Previous studies demonstrated that negative biasing is observed after a bout of egestive activity (Proekt et al., 2004, 2007). Namely, when there is an attempt to switch to ingestion it cannot be done. For example, stimulation of the ingestive CPG input (CBI-2) triggers a cycle of activity that is egestive. We hypothesized that the outward current induced when egestive priming occurs might be partially responsible for this biasing. Consistent with this idea, we demonstrate that the outward current persists long enough to be present during a task switch. Further dynamic clamp manipulation of the current impacts the ingestive versus egestive nature of cycles of activity induced during switching. In summary, we demonstrate that the physiological significance of a persistent current induced under one set of circumstances may not become apparent until there is a subsequent task switch.

\section{Materials and Methods}

Animals. Adult sea slugs (Aplysia california) were purchased from Marinus Scientific and maintained in artificial seawater (ASW) (Instant Ocean) at $15^{\circ} \mathrm{C}-18^{\circ} \mathrm{C}$. Aplysia are hermaphrodites, and are therefore both male and female. Animals weighing 150-200 g were anesthetized by injection of 90-120 ml isotonic (i.e., $337 \mathrm{mM}$ ) $\mathrm{MgCl}_{2}$. Cerebral and buccal ganglia were dissected out with the cerebral-buccal connectives, esophageal, and buccal nerves intact. The connective tissue surrounding ganglia was removed while ganglia were bathed in a solution containing $50 \%$ ASW (in mM as follows: $460 \mathrm{NaCl}, 10 \mathrm{KCl}, 55 \mathrm{MgCl}_{2}, 11 \mathrm{CaCl}_{2}$, and 10 HEPES buffer, $\mathrm{pH} 7.6$ ) and $50 \%$ isotonic $\mathrm{MgCl}_{2}$. Desheathed ganglia were then superfused with ASW at $0.3 \mathrm{ml} / \mathrm{min}$ and maintained at $\sim 14^{\circ}$ $\mathrm{C}-17^{\circ} \mathrm{C}$. A reduced preparation consisting of only the buccal ganglia was used in experiments where effects of peptides on B8 currents and excitability were measured. When currents were induced by exogenous peptides, buccal hemiganglia were truncated near the buccal commissure to improve the space clamp.

Cell identification. Neurons were identified based on their location, size, electrophysiological, and morphologic characteristics. Neurons recorded from these experiments are cerebral-buccal interneuron 2 (CBI-2) and B8. CBI-2 is a command-like neuron that triggers ingestive motor programs (Rosen et al., 1991). It is located in the M-cluster of the cerebral ganglion (Rosen et al., 1991; Hurwitz et al., 1999). B8 is a radula closer motor neuron, and it is located on the ventrolateral surface of the buccal ganglion (Morton and Chiel, 1993a,b).

Electrophysiological recordings. Intracellular recordings were obtained using glass micropipettes filled with a $0.6 \mathrm{M} \mathrm{K}_{2} \mathrm{SO}_{4}$ and $60 \mathrm{~mm}$ $\mathrm{KCl}$ electrolyte solution. Electrodes were fabricated using a Flaming/ Brown micropipette puller (Sutter Instrument) to yield a final resistance of 6-10 $\mathrm{M} \Omega$. Electrodes were held in HS-2A headstages (Molecular Devices) connected to AxoClamp 2B amplifiers (Molecular Devices). Extracellular nerve recordings were obtained from the EN and I2 nerves using polyethelene suction electrodes connected to a model 1700 differential AC amplifier (bandpass 0.1-1 kHz) (A-M Systems). Both intracellular and extracellular signals were digitized using a Digidata $1320 \mathrm{~A}$ (Molecular Devices). Data were acquired using Clampex for voltageclamp experiments, or AxoScope software (Molecular Devices).

Classification of feeding motor programs. Feeding behaviors in Aplysia can be classified as egestive or ingestive (Kupfermann, 1974; Morton and Chiel, 1993a,b). In both cases, the radula (food-grasping organ) initially protracts. Subsequently, the radula retracts. Behaviors differ in the relative timing of radula opening and closing. In ingestion, the radula is open during protraction and closed during retraction (Morton and Chiel, 1993a,b). This pulls food into the mouth. In egestion, the radula is open during retraction and closed during protraction. This pushes food out (Morton and Chiel, 1993a,b).

In vitro, motor activity was classified as has been previously described (Morton and Chiel, 1993a,b; Jing and Weiss, 2001, 2002; Jing et al., 2004; Proekt et al., 2004, 2007; Friedman and Weiss, 2010). The protraction phase of the motor program was monitored by recording from the I2 nerve, which contains the axons of protraction motor neurons (Hurwitz and Susswein, 1996; Nargeot et al., 1999; Morgan et al., 2000; Jing and Weiss, 2001, 2002). Retraction was defined by the cessation of activity in the I2 nerve and by depolarization in B8. Radula closing was monitored by recording from the B8 motor neurons (Morton and Chiel, 1993a,b). Activity was classified as ingestive when the B8 firing frequency during protraction was $<3.5 \mathrm{~Hz}$, the firing frequency during retraction was $>4.5 \mathrm{~Hz}$, and the ratio of the two numbers was $<0.65$ (Morgan et al., $2000,2002)$. Activity was classified as egestive when the B8 firing frequency during protraction was $>3.5 \mathrm{~Hz}$, the firing frequency during retraction was $<2.5 \mathrm{~Hz}$, and the ratio of the two numbers was $>2.0$ (Morgan et al., 2000, 2002). Motor activity was considered intermediate when B8 fired at a low frequency during both protraction and retraction (Proekt et al., 2004; Dacks and Weiss, 2013).

Induction of ingestive and egestive repetition priming. Ingestive motor programs were triggered using CBI-2, which receives excitatory input from sensory neurons activated by food (Rosen et al., 1991). CBI-2 was intracellularly stimulated during the protraction phase of the motor program at $9 \mathrm{~Hz}$ with brief $(15 \mathrm{~ms})$ current pulses to elicit one-for-one action potentials (e.g., Friedman and Weiss, 2010). Single cycles of motor activity triggered in this manner most commonly had intermediate characteristics (as has been previously reported) (Proekt et al., 2004). Activity became ingestive when we "primed" preparations by repeatedly inducing motor activity with a relatively short intercycle interval (Proekt et al., 2004). In most experiments, we stimulated CBI-2, so that 7-10 cycles of motor activity were triggered with $30 \mathrm{~s}$ between the termination of the retraction phase of one cycle and the initiation of the protraction phase of the following cycle (Friedman and Weiss, 2010).

Egestive motor programs were triggered via extracellular stimulation of a branch of the EN that contains processes of sensory neurons innervating the gut (Kuslansky et al., 1987). To induce priming, the EN was stimulated continuously with $\sim 4-8 \mathrm{~V}, 3 \mathrm{~ms}$ pulses at $2 \mathrm{~Hz}$ for $2 \mathrm{~min}$. The pulse amplitude was adjusted to elicit five successive cycles of activity (Fig. 1A) (Proekt et al., 2004; Friedman et al., 2009; Siniscalchi et al., 2016).

Exogenous peptides. Lyophilized aliquots of peptides were dissolved in $50-100 \mu$ of deionized $\mathrm{H}_{2} \mathrm{O}$, then diluted to working concentrations in the carrier solution for bath perfusion. Carrier solutions were ASW, high divalent ASW (HiDi; $368 \mathrm{~mm} \mathrm{NaCl}, 10 \mathrm{~mm} \mathrm{KCl,} 101 \mathrm{~mm} \mathrm{MgCl}_{2}$, 
A

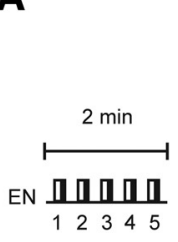

B cycle

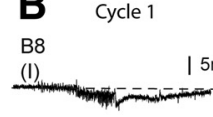

Cycle 2
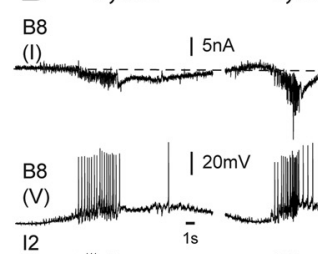
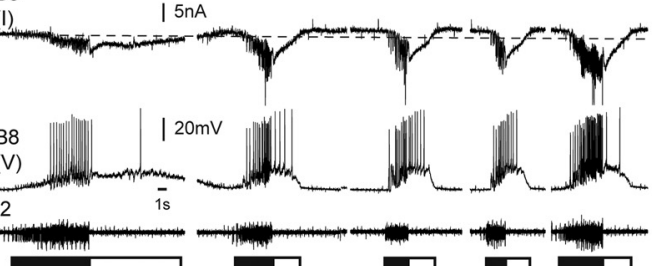

(1)

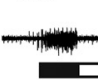

Figure 1. An outward current is induced during egestive repetition priming. $A$, Five cycles of motor activity were generated by stimulating the EN for 2 min. $B$, Top, Recording from a B8 radula closer motor neuron under voltage-clamp conditions. Dashed line indicates the B8 holding potential $(-60 \mathrm{mV})$. Middle, Current-clamp B8 recording. Bottom, Extracellular recording from the $\mathrm{I} 2$ nerve. All recordings were made simultaneously. Bars under the recordings represent the protraction (closed bar) and retraction (open bar) phases of the motor program. $\mathbf{C}$, Mean tonic currents recorded just before the first and fifth cycles. Plotted are mean \pm SEM with overlying scatter plots $(n=6)$. Currents are outward, and the current after the fifth cycle is larger than the current after the first cycle. $\boldsymbol{D}$, Mean net (synaptic-tonic) currents for cycle 1 versus cycle 5 . Net currents are inward, and the cycle 5 current is larger than the cycle 1 current. $* p<0.05$. $* * p<0.01$.

$13.8 \mathrm{~mm} \mathrm{CaCl}_{2}$, and $10 \mathrm{~mm}$ HEPES, pH 7.6), or ASW containing $40 \mu \mathrm{M}$ TTX citrate (Tocris Bioscience).

Voltage-clamp characterization of currents induced during motor programs. Two-electrode voltage-clamp techniques were used to characterize currents induced in $\mathrm{B} 8$ during motor programs. In these experiments, B8 was held at its normal resting membrane potential $(-60 \mathrm{mV})$, and tonic currents were evaluated by calculating the mean current in the $2 \mathrm{~s}$ period preceding each cycle of the motor program (Perkins et al., 2018). Phasic (presumably synaptic) currents were evaluated by measuring the peak total inward current induced in B8 during protraction and subtracting any tonic current that was present (Perkins et al., 2018).

Voltage-clamp characterization of currents induced by EN stimulation and peptide application. In some experiments, currents were measured using a step protocol. Steps ranged from $-100 \mathrm{mV}$ to $-50 \mathrm{mV}$ or $-40 \mathrm{mV}$ and were delivered in $10 \mathrm{mV}$ increments with an interval of 590 s. Steps to membrane potentials closer to the holding potential were applied every $5-15 \mathrm{~s}$, whereas steps far away from the holding potential were separated by 60-90 s. Steady-state current-voltage curves were constructed by averaging the clamp current in the last $100 \mathrm{~ms}$ of the voltage step. In other experiments, currents were measured using a ramp protocol. Ramps were delivered either in ascending or descending order from $-100 \mathrm{mV}$ to $-40 \mathrm{mV}$ at $5 \mathrm{mV} / \mathrm{s}$.

To characterize currents induced by modulators or nerve stimulation, difference curves were generated by subtracting currents generated under control conditions from currents induced by peptides or by stimulating the EN. In EN experiments, it was not possible to deliver all the voltage steps in a single run (the current did not persist long enough). Consequently, one or two voltage steps were delivered at a time. Preparations were rested for $30 \mathrm{~min}$ and the next set of steps applied. This was repeated until the full voltage range had been covered.

Effects of peptides and EN stimulation on excitability. To determine effects of peptides and EN stimulation on B8 excitability, action potentials were elicited by injecting $2-4 \mathrm{nA}, 3$ or $4 \mathrm{~s}$ constant current depolarizing pulses every $30 \mathrm{~s}$. The specific amount of current injected in an individual experiment was selected to generate a relatively consistent number of spikes under control conditions. The number of spikes triggered under control conditions was then compared with the number of spikes triggered after either EN stimulation or peptide application. Three stable responses were obtained before each experimental manipulation. The control excitability was calculated by averaging the number of spikes triggered during these three trials.

Dynamic clamp manipulation of currents. Dynamic clamp experiments used the NetClamp http://systemsneuroscience.website/NetClamp/ suite of Dynamic Clamp software and a National Instruments PCI-6036E data acquisition board, as has been described previously (Perkins et al., 2018). In general, the dynamic clamp current was calculated using the following equation:

$$
I_{x}=\bar{g}_{x} * m_{x}^{p} * h_{x}^{p} *\left(V-E_{x}\right)
$$

In our experiments, $V$ is the membrane potential of B8, $x$ the modeled outward current, $m_{x}$ the activation gate, $h_{x}$ the inactivation gate, $\overline{g_{x}}$
Table 1. Parameters used in dynamic clamp experiments

\begin{tabular}{lllllllllll}
\hline & $g_{\max }(\mathrm{nS})$ & $\mathrm{E}_{\mathrm{rev}}(\mathrm{mV})$ & $\mathrm{V}_{\mathrm{m}}(\mathrm{mV})$ & $\mathrm{K}_{\mathrm{m}}(\mathrm{mV})$ & $\tau(\mathrm{ms})$ & $p$ & $V_{\mathrm{h}}(\mathrm{mV})$ & $\mathrm{K}_{\mathrm{h}}(\mathrm{mV})$ & $\tau_{\mathrm{h}}(\mathrm{ms})$ & $q$ \\
\hline$l_{\text {Egst }}$ & 2 & -80 & -80 & -5 & 20 & 1 & -10 & 10 & 20 & 1 \\
\hline
\end{tabular}

the maximum conductance, $E_{x}$ the reversal potential, and $p$ and $q$ are non-negative integers. Activation and inactivation depend on $V$ in a sigmoidal fashion as follows:

$$
\begin{aligned}
& \frac{d x}{d t}=\frac{1}{\tau x}(x \infty(V)-x) \\
& x \infty(V)=\frac{1}{1+\exp ((V-V x) / k x} \\
& \tau x=0.02
\end{aligned}
$$

Where $x$ is an activation or inactivation gate (i.e., $m$ or $h$ in Eq. 1). To model the current induced by egestive priming or FRFa, we sought to capture its notable features, that is, the fact that it reversed at a membrane potential that was more hyperpolarized than the normal resting membrane potential, and the fact the current induced increased with depolarization. We created a single-model current with voltage-dependent activation and inactivation that captured these features as follows:

$$
I_{E g s t}=\bar{g}_{E g s t} * m_{E g s t}^{p} * h_{E g s t}^{q} *(V-E E g s t)
$$

The parameters for the current, $I_{\text {Egst }}$ are listed in Table 1.

When simultaneous dynamic clamp current and constant current injection were required, the constant current injection was generated via a TTL trigger to the step command input of the AxoClamp 2B, which was connected to the National Instrument board. The dynamic clamp frequency was set at $5 \mathrm{kHz}$.

Statistics. Data were analyzed in Clampfit and Spike 2 (Cambridge Electronic Design) and organized in Excel. Data were plotted and analyzed in Prism (GraphPad Software). Error bars indicate SEM, and the significance level was set at $p<0.05$. Where applicable, measurements under different conditions were treated as repeated measures as indicated in the text. Throughout the results, $n$ refers to the number of preparations.

\section{Results}

Previous experiments established that egestive repetition priming occurs in the Aplysia feeding network (Proekt et al., 2004, 2007; Friedman et al., 2009, 2015). Specifically, when cycles of motor activity are repeatedly triggered by stimulating the EN, they become more and more egestive. An egestive motor program is defined as one in which the B8 radula closer motor neurons fire at a relatively high frequency during the radula protraction phase 

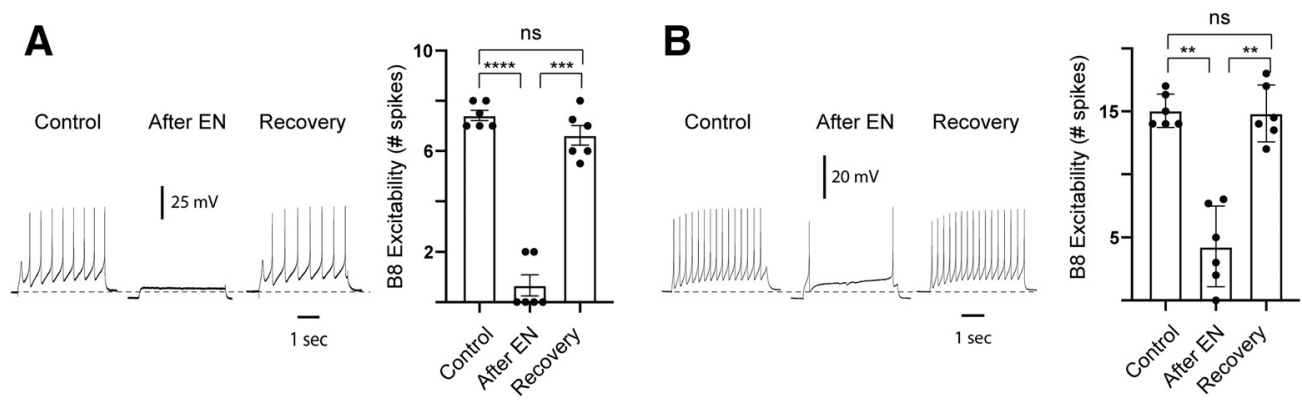

Figure 2. EN stimulation reduces the excitability of B8. $\boldsymbol{A}$ (left), $\boldsymbol{B}$ (left), Excitability was measured by injecting constant current pulses before EN stimulation (control) and $\sim 30 \mathrm{~s}$ after egestive repetition priming (after EN). Dashed lines indicate the resting membrane potential before EN stimulation. Recovery recordings were obtained $\sim 10$ min after EN stimulation. $A$, Small current pulses were injected that triggered $\sim 7$ spikes before EN stimulation. $\boldsymbol{B}$, Pulses were larger and triggered $\sim 14$ spikes. In both cases, EN stimulation produced a significant decrease in spike number $(n=6$ for both $\boldsymbol{A}$ and $\boldsymbol{B})$. n.s., Not significant, $p>0.05 . * * p<0.01 . * * * p<0.001$. $* * * * p<0.0001$.

of the motor program (if the radula closes as it moves forward, food is pushed out of the buccal cavity) (Kupfermann, 1974; Morton and Chiel, 1993a,b).

A previous study sought to determine whether the progressive increase in the B8 firing frequency observed during egestive priming was paralleled by an increase in synaptic input (Wang et al., 2019). In these experiments, priming was induced (as shown in Fig. 1A), and we simultaneously recorded from two B8 neurons. One recording was obtained under current-clamp conditions (Fig. $1 B$, middle) to verify that priming occurred (i.e., that the B8 firing frequency increased). The second recording was obtained under voltage-clamp techniques (Fig. $1 B$, top) to determine whether there was an increase in the inward current induced during the protraction phase of the motor program (i.e., during the phase of the motor program in which there is a firing frequency increase). We found that the inward current during protraction did increase (Wang et al., 2019). We now report that additionally a small persistent (tonic) current also develops in $\mathrm{B} 8$ as priming develops (Fig. 1C; for the comparison of the current before and after priming, paired $t$ test; $n=6 ; t_{(5)}=$ $\left.3.5, p=1.7 \times 10^{-2}\right)$. Interestingly, however, this current is outward, rather than inward, and would be expected to decrease, rather than increase, excitability. However, the outward current is apparently small relative to the phasic inward current (Fig. 1B); that is, the net current (phasic minus tonic) is significantly inward (Fig. $1 D$; for the comparison of the net current before and after priming, paired $t$ test; $t_{(5)}=5.6$, $\left.p=2.5 \times 10^{-3}\right)$. Consequently, the net effect is a firing frequency increase (Wang et al., 2019).

Although the tonic outward current that developed during EN stimulation was relatively small at the B8 holding potential $(-60 \mathrm{mV})$, if it was voltage-dependent, it could be larger during protraction when $\mathrm{B} 8$ receives depolarizing synaptic input. If so, current induction could significantly impact excitability. To determine whether this is likely to be the case we measured B8 excitability before and after EN stimulation by injecting depolarizing constant current pulses (Fig. $2 A, B$ ). Pulses of different sizes were injected to cover a range of $B 8$ firing frequencies. EN stimulation had a significant effect when relatively small current pulses were injected so that $\sim 7$ spikes were triggered in B8 (Fig. $2 A$; one-way repeated-measures ANOVA; $n=6 ; F_{(1.4,7.0)}=132.6$, $p=1.0 \times 10^{-4}$; Tukey's post hoc comparisons, $p<1.0 \times 10^{-4}$ for control vs EN, $p=3.0 \times 10^{-4}$ for EN vs recovery, and $p=0.1$ for control vs recovery). Additionally, EN stimulation was effective when larger current pulses were injected so that $\sim 14$ spikes were triggered (Fig. 2B; one-way repeated-measures ANOVA; $n=6$; $F_{(1.3,6.6)}=41.9, p=3.0 \times 10^{-4}$; Tukey's post hoc comparisons, $p=3.3 \times 10^{-3}$ for control vs $\mathrm{EN}, p=1.5 \times 10^{-3}$ for $\mathrm{EN}$ vs recovery, and $p=1.0$ for control vs recovery).

To confirm that current induction itself can modify excitability, it is necessary to manipulate it. This can be accomplished using dynamic clamp techniques if the $I-V$ characteristics of the current are known. To characterize the current, we held B8 at $-60 \mathrm{mV}$ (its normal resting potential) and its steady-state current-voltage relationship was determined by applying $2 \mathrm{~s}$ command steps that ranged from $-100 \mathrm{mV}$ to $-50 \mathrm{mV}$ in $10 \mathrm{mV}$ increments (Fig. 3A1). Although voltages more depolarized than $-50 \mathrm{mV}$ were of interest, depolarizations beyond this point trigger spiking in the B8 axon in the intact buccal ganglion (the preparation required to study effects of endogenous modulator release from the EN). Currents induced by EN stimulation were computed by subtracting currents measured in the rested preparation from currents measured after 2 min of EN stimulation (Fig. 3A1). EN stimulation induced a current that reversed and was outward at more depolarized potentials (Fig. $3 A 2 ; n=7$ ). In other experiments, B8 was again held at $-60 \mathrm{mV}$, and currents were measured using a ramp protocol $(-100 \mathrm{mV}$ to $-50 \mathrm{mV}$ at $5 \mathrm{mV} / \mathrm{s}$ ). Results were qualitatively similar (Fig. $3 B ; n=7$ ).

During motor programs, B8 receives synaptic input and reaches potentials that are more depolarized than $-50 \mathrm{mV}$ (the limit of the EN voltage-clamp experiments) (e.g., Fig. $1 B$ ). Steps to potentials more depolarized than $-50 \mathrm{mV}$ are only possible when the B8 axon is truncated. However, the surgery that is necessary to accomplish this generally disrupts the network of neurons that mediate motor activity. To identify an alternative to EN stimulation that could be used to induce the current of interest, we conducted experiments designed to determine whether we could identify the neurotransmitter that is responsible for the excitability decrease. (Experiments in which currents are induced via application of exogenous substances can be conducted in dissected preparations.)

Previous studies demonstrated that neuropeptides released from CPG inputs play a predominant role in the induction of the egestive state (Jing et al., 2007; Vilim et al., 2010; Wu et al., 2010; Friedman et al., 2015). Four types of peptides are released when the EN is stimulated; the small cardioactive peptides (SCPs), FMRFamide, the FRFamide peptides, and an Aplysia version of neuropeptide Y (apNPY) (Jing et al., 2007; Vilim et al., 2010; Wu et al., 2010). We tested all four types of peptides. The SCP precursor encodes two peptides: SCPa and SCPb (Mahon et al., 1985). Both peptides are present as a single copy, and have been described as having the same bioactivity (e.g., Lloyd et al., 1988). Our experiments were conducted with SCPb. The FRFamide peptides are part of a family of five peptides (FRFa-e) (Cropper 
$\begin{array}{ll}\text { A1 } & \text { A2 }\end{array}$

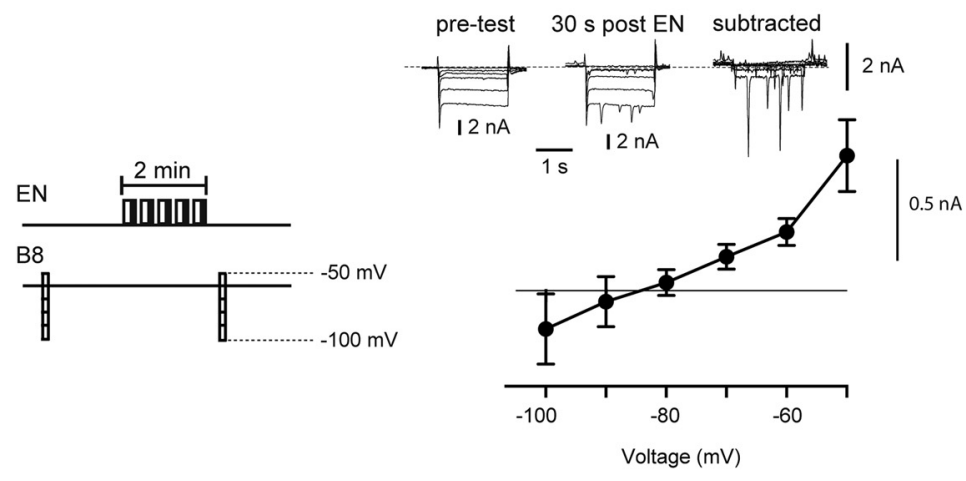

B

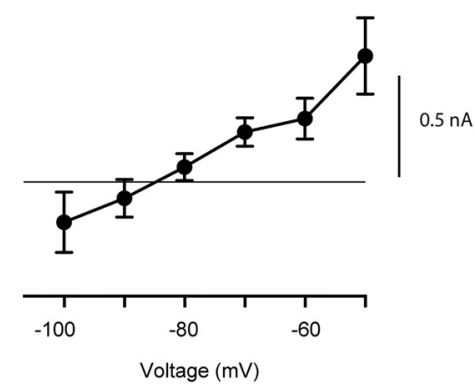

Figure 3. $I-V$ characteristics of the current induced by egestive priming. $A$, Measurement of currents using a step protocol. B8 was held at $-60 \mathrm{mV}$, and the steady-state current-voltage relationship was determined by applying $2 \mathrm{~s}$ steps that ranged from -100 to $-50 \mathrm{mV}$ in $10 \mathrm{mV}$ increments $(\boldsymbol{A} \mathbf{1})$. Priming induced a current that reversed at $\sim-80 \mathrm{mV}$ and was outward at more depolarized potentials $(\boldsymbol{A 2} ; n=7)$. $\boldsymbol{A} 2$, Inset, Sample recordings of current steps injected before EN stimulation (pretest), after EN stimulation (30 s post-EN), and results of the subtraction (subtracted). $\boldsymbol{B}$, Measurements of currents using a ramp protocol. B8 was held at $-60 \mathrm{mV}$ and depolarized from -100 to $-50 \mathrm{mV}$ at $5 \mathrm{mV} / \mathrm{s}$. Similar results were obtained ( $n=7$ ).

et al., 1994; Vilim et al., 2010). Our experiments were conducted with FRFa, which is the most abundant member of the family.

When peptides were applied in normal ASW, only two (FRFa and $\mathrm{SCPb}$ ) mimicked the effect of EN stimulation (i.e., decreased B8 excitability) (Fig. 4A1,A2). FMRFamide increased excitability (Fig. $4 B$; one-way repeated-measures ANOVA; $n=5 ; F_{(1.96,7.83)}=$ 224.0, $p=1.0 \times 10^{-6}$; Tukey's post hoc comparisons, control vs peptide peak $p=1.3 \times 10^{-4}$, control vs peptide steady state $p=8.2 \times 10^{-3}$, control vs recovery $p=2.8 \times 10^{-1}$, peptide peak vs peptide steady state $p=1.2 \times 10^{-3}$, peak peptide vs recovery $p=9.2 \times 10^{-5}$, peptide steady state vs recovery $p=4.4 \times 10^{-3}$ ). apNPY induced intermittent spontaneous activity when it was applied in ASW, making it difficult to assess direct effects on B8 (not shown). When it was applied in a HiDi saline (where there was little to no impact on spontaneous activity), it had no effect at either a high or low concentration (Fig. $4 C$; one-way repeatedmeasures ANOVA; $n=5$; for application at $0.1 \mu \mathrm{M}, F_{(1.69,6.76)}=$ 1.7, $p=0.2442$; for application at $10 \mu \mathrm{M}, F_{(1.11,4.45)}=1.2$, $p=0.33$ ). To determine whether their effects were direct, FRFa and $\mathrm{SCPb}$ were applied in HiDi. The switch to HiDi had no impact on results obtained with $\mathrm{FRFa}$ (Fig. 4A1; two-way repeated-measures ANOVA; $n=10$; for the effect of peptide application, $F_{(2,16)}=330.5, p<1.0 \times 10^{-7}$; Bonferroni's post hoc comparisons, ASW control vs peptide $p<1.0 \times 10^{-4}$, ASW peptide vs recovery $p<1 \times 10^{-4}$, ASW control vs recovery $p=1.0$, HiDi control vs peptide $p<1.0 \times 10^{-4}$, HiDi peptide vs recovery $p<1.0 \times 10^{-4}$, HiDi control vs recovery $p=1.0$; for ASW vs HiDi, $F_{(1,8)}=0.1, p=0.7$, ASW peptide vs HiDi peptide $p=1.0$ ). The switch did, however, impact results obtained with $\mathrm{SCPb}$ (Fig. 4A2; two-way repeated-measures ANOVA; $n=10$; for the effect of peptide $F_{(1.4,11.5)}=306.3, p<1.0 \times 10^{-8}$, Bonferroni's post hoc comparisons, ASW control vs peptide $p=6.3 \times 10^{-4}$, ASW peptide vs recovery $p=4.4 \times 10^{-4}$, ASW control vs recovery $p=0.2$, HiDi control vs peptide $p=2.5 \times 10^{-3}$, HiDi peptide vs recovery $p=1.1 \times 10^{-2}$, HiDi control vs recovery $p=1.0$; for ASW vs HiDi, $F_{(1,8)}=45.7, p=1.4 \times 10^{-4}$, ASW peptide vs HiDi peptide $\left.p=1.4 \times 10^{-3}\right)$. This indicates that effects of FRFa application are direct, whereas effects of $\mathrm{SCPb}$ application are primarily indirect.

In the HiDi versus ASW experiments shown in Figure $4 A 1$, $A 2$, peptides were applied at a concentration that is commonly used in CNS experiments ( $1 \mu \mathrm{M})$ (e.g., Furukawa et al., 2001; Jing et al., 2007, 2010; Vilim et al., 2010). In some cases, peptides are inhibitory at one concentration, and excitatory at another (presumably because of activation of two types of receptors) (e.g., Brezina et al., 1995). To determine whether FRFa is inhibitory at concentrations other than $1 \mu \mathrm{M}$, we applied it at 0.1 and $10 \mu \mathrm{M}$. In both cases, inhibition was observed (Fig. $4 B$; for both concentrations, one-way repeated-measures ANOVA; $n=5$; for $0.1 \mu \mathrm{M} ; F_{(1.1,4.3)}=3.5 \times 10^{2}, p=3.2 \times 10^{-3}$, Tukey's post hoc comparisons, control vs peptide $p=8.2 \times 10^{-3}$, peptide vs recovery $p=9.1 \times 10^{-3}$, control vs recovery $p=0.18$; for $10 \mu \mathrm{M} ; F_{(1.2,5.0)}=$ $2.5 \times 10^{3}, p<1.0 \times 10^{-7}$, Tukey's post hoc comparisons, control vs peptide $p=2.0 \times 10^{-7}$, peptide vs recovery $p<1.0 \times 10^{-7}$, control vs recovery $p=8.8 \times 10^{-1}$ ). Together, these data suggest that effects of EN stimulation are most likely to be mediated by release of the FRFamide peptides.

To confirm this, we sought to determine whether FRFa application occludes the effect of EN stimulation. We measured B8 excitability after EN stimulation in normal ASW, and after EN stimulation in the presence of $5 \mu \mathrm{m}$ peptide (Fig. 5). As expected, EN stimulation decreased excitability in normal ASW (one-way repeated-measures ANOVA; $n=6 ; F_{(1.6,7.8)}=97.22, p<1.0 \times$ $10^{-4}$, Tukey's post hoc comparisons, control vs EN stimulation $p=2.0 \times 10^{-4}$, control vs recovery $p=4.4 \times 10^{-1}$, EN stimulation vs recovery $p=5.0 \times 10^{-4}$ ). In experiments with preapplication of peptide, the FRFa application at the beginning of the experiment decreased excitability (as expected) (one-way repeatedmeasures ANOVA; $n=6 ; F_{(2.1,10.3)}=37.7, p<1.0 \times 10^{-4}$, Tukey's post hoc comparisons, control vs FRFa $p=1.5 \times 10^{-3}$ ). Consequently, we increased the size of injected current pulses so that the number of spikes triggered in the presence of peptide was comparable to the number triggered before peptide (control vs FRF plus current, $\left.p=3.8 \times 10^{-1}\right)$. Finally, we stimulated the EN to determine whether a further excitability decrease would be observed. We found that it was not (FRFa plus current vs FRFa plus current postEN $p=9.2 \times 10^{-1}$ ). These data indicate that FRFa plays a major role in mediating effects of EN stimulation on B8.

To characterize effects of FRFa on B8, we conducted voltageclamp experiments in preparations in which the B8 axon was truncated. This reduces the $\mathrm{B} 8$ length constant and makes it electrically more compact. We induced currents using a ramp protocol that went from $-100 \mathrm{mV}$ to $-40 \mathrm{mV}$ at $5 \mathrm{mV} / \mathrm{s}$. Currents induced by peptide were computed by subtracting currents measured in rested preparations from currents measured after peptide application. FRFa was applied in normal ASW, and in ASW containing $40 \mu \mathrm{M}$ TTX (to block activity in the ganglion). Currents induced under the two conditions were not significantly 



B

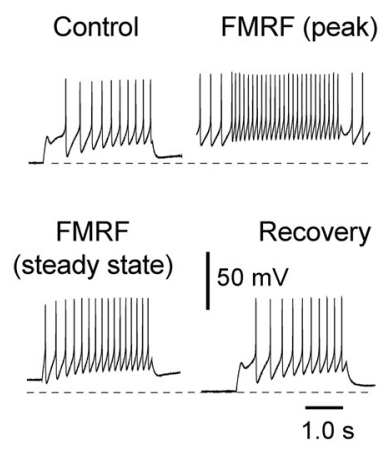

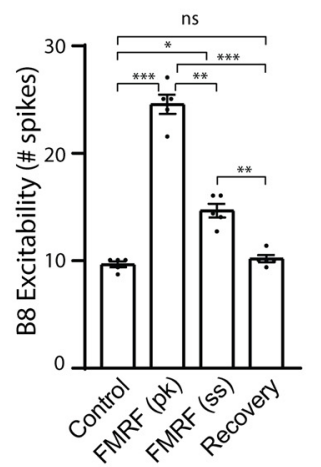

C

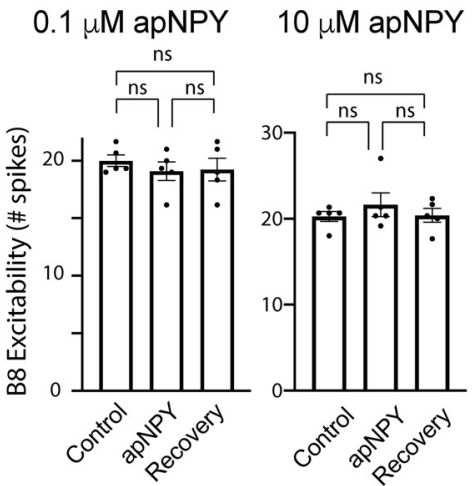

D $0.1 \mu \mathrm{M}$ FRFa

$10 \mu \mathrm{M}$ FRFa

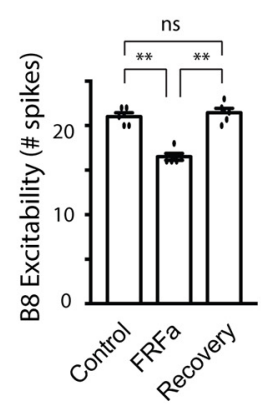

Figure 4. Effects of exogenous peptides on B8 excitability. A-D, Excitability was measured by injecting constant current pulses into B8 so that $\sim 20$ spikes were evoked. Dashed lines indicate the resting membrane potential before peptide application. $\boldsymbol{A}$, Peptides that mimic effects of EN stimulation. Excitability was measured in normal ASW (black traces and data), and in a HiDi saline (red traces and data), before peptide application (control), in the presence of $1 \mu \mathrm{m} \mathrm{FRFa}(\boldsymbol{A})$ and $1 \mu \mathrm{m} \mathrm{SCPb}(\boldsymbol{B})$, and after peptide washout (recovery). The switch to HiDi saline had no effect on results obtained by applying FRFa $(n=5)$. It did, however, largely eliminate the effects of SCPb $(n=5)$. $\boldsymbol{B}$, FMRFamide increased excitability. There was a peak increase, and then excitability stabilized at a slightly lower, steady-state level $(n=5)$. C, apNPY had no effect on excitability applied at either a relatively low $(0.1 \mu \mathrm{m})$ or high $(10 \mu \mathrm{m})$ concentration $(n=5)$. $\boldsymbol{D}$, Effects of FRFa at a higher $(10 \mu \mathrm{M}, n=5)$ and lower $(0.1 \mu \mathrm{m}, n=5)$ concentration. Effects are still inhibitory. n.s., Not significant, $p>0.05 . * p>0.05 . * * p<0.01$. $* * * p<0.001$. $* * * * p<0.0001$.

different (Fig. 6; two-way repeated-measures ANOVA; $n=5$; $\left.F_{(1,9)}=1.0 \times 10^{-2}, p=0.9\right)$, and in the -100 to $-50 \mathrm{mV}$ range were qualitatively similar to currents induced by EN stimulation. Of particular interest was the current induced at $-40 \mathrm{mV}$ (the potential we were not able to reach in the EN voltage-clamp experiments). The mean current at $-40 \mathrm{mV}$ was larger than the current induced at $-50 \mathrm{mV}$ (Fig. 6; paired $t$ test; $n=11 ; t_{(10)}=13.1, p=1.0 \times 10^{-7}$ ).

Knowing the $I-V$ characteristics of the outward current enabled us to add it to B8 neurons using dynamic clamp techniques to determine whether excitability would be impacted. We measured the current-frequency relationship in normal B8 neurons (no artificial current introduction) under control conditions, and after EN stimulation. As expected, EN stimulation decreased the slope of the current-frequency relationship. The slope went from to 1.7 to $1.1 \mathrm{~Hz} / \mathrm{nA}$ (Fig. 7, filled circles vs open circles; $t$ test; $n=10$ for control and $n=4$ for EN stimulation; $\left.t_{(20)}=3.4, p=3.1 \times 10^{-3}\right)$. We then compared this change to the decrease observed when the outward current was artificially introduced. When the current was introduced at $100 \% \mathrm{~g}_{\max }$, the slope was $1.2 \mathrm{~Hz} / \mathrm{nA}$, which was less than the slope observed under control conditions (Fig. 7, filled black circles vs filled green triangles; $t$ test; $n=10$ for control conditions and $n=5$ for dynamic clamp current addition with $100 \% \mathrm{~g}_{\max } ; t_{(22)}=2.8, p=$ $\left.1.1 \times 10^{-2}\right)$. Further, it was not significantly different from the slope observed after EN stimulation (Fig. 7; filled green triangles vs open circles; $t$ test; $t_{(8)}=0.9, p=0.4$ ). To determine how dependent our results were on the specific parameters used, we reduced $g_{\max }$ so that it was $80 \%$. When the current was introduced this way, the slope was $1.3 \mathrm{~Hz} / \mathrm{nA}$, which was not significantly different from the slope at $100 \% \mathrm{~g}_{\max }$ (Fig. 7 , open green triangles vs closed green triangles; $t$ test; $n=5$ for $\left.80 \% \mathrm{~g}_{\max } ; t_{(9)}=0.5, p=0.7\right)$. These data indicate that 



Figure 5. Effect of EN stimulation on B8 excitability in the presence of FRFa. Excitability was measured by injecting constant current pulses into B8 so that $\sim 20$ spikes were triggered. Effects of EN were initially determined in normal ASW (inset above left panel). As expected, EN stimulation decreased excitability. Subsequently, effects of EN stimulation were determined in $5 \mu \mathrm{m}$ FRFa using the protocol shown in the inset above the middle panel. FRFa decreased excitability. Consequently, the size of the current pulse was adjusted so that $\sim 20$ spikes were induced. EN stimulation had no further effect on excitability. After the occlusion experiment, preparations were retested to verify that EN stimulation still reduced excitability (right) $(n=6)$. n.s., Not significant, $* * p<0.01$. $* * * p<0.001$.

dynamic clamp introduction of the outward current is sufficient to modify the B8 excitability.

Together, the above data indicate that an outward current is induced during egestive repetition priming that is "counterproductive" in that it decreases, rather than increases, B8 excitability. Induction of this current is, to a large extent, mediated by release of the FRFa peptides from the EN. Peptide-mediated effects often persist beyond periods of neural activity. It was of interest to determine whether this is also the case for the outward current characterized in this study because a persistent effect could play a role during task switching. To test for persistence, we repeatedly stimulated the EN and measured the outward current induced by stepping to $-55 \mathrm{mV}$ at various time points (Fig. $8 A$ ). We found that the current did persist long enough to impact task switching, which can occur after $\sim 30 \mathrm{~s}$ (Fig. $8 B$; one-way ANOVA; $n=9$; $\left.F_{(6,56)}=10.76 ; p<1.0 \times 10^{-5}\right)$.

One type of task switching observed in Aplysia involves switches from egestive to ingestive behavior (Proekt et al., 2008).
When this occurs in vitro, biasing is observed. If egestive priming is induced by repeatedly stimulating the EN and then a cycle of activity is triggered by stimulating the ingestive input to the feeding CPG (CBI-2), the cycle of activity is egestive (Proekt et al., 2004). (In a rested preparation, a single cycle of CBI-2 induced activity is not egestive; instead, it has intermediate characteristics.) Thus, the bias has been referred to as "negative" since CBI2 triggers egestive rather than intermediate activity.

To determine how egestive repetition priming impacts a series of CBI-2-induced cycles of activity (as opposed to a single cycle), we stimulated CBI-2 to characterize the progression of ingestive repetition priming when there is no task switch (Fig. $9 A$, left). We then conducted experiments in which ingestive repetition priming was preceded by a bout of egestive priming (Fig. $9 A$, right). Ingestive priming was altered (Fig. 9B; two-way repeated-measures ANOVA; $\left.n=7 ; F_{(1,12)}=6.2, p=2.8 \times 10^{-2}\right)$. For example, without the task switch, the mean B8 firing frequency during retraction was $\sim 4 \mathrm{~Hz}$ (the frequency that induces 


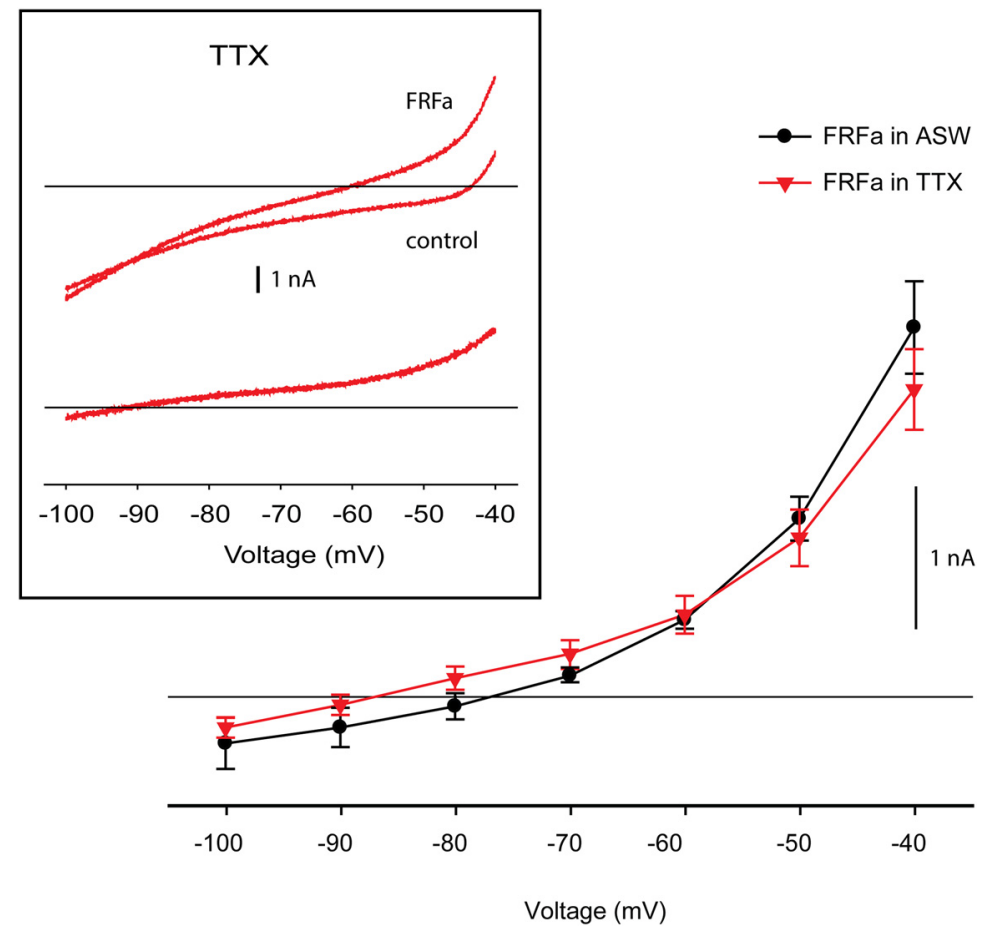

Figure 6. $\quad I-V$ characteristics of the current induced by FRFa. Currents were generated using a ramp protocol that went from $-100 \mathrm{mV}$ to $-40 \mathrm{mV}$ at $5 \mathrm{mV} / \mathrm{s}$. Currents induced by peptide were computed by subtracting currents measured in rested preparations from currents measured after peptide application. Inset, Top, Examples of raw traces. Bottom, The derived subtracted current. Right, Group data are plotted. Experiments were conducted when FRFa was applied in normal ASW (black), and when FRFamide was applied in ASW containing $40 \mu \mathrm{m}$ TTX (red). Note the similarity between the currents induced under the two conditions $(n=5)$.

functional closing) (Friedman et al., 2009) during the third cycle of induced activity. When there was a task switch, B8 did not fire at this frequency until the seventh cycle. These data indicate that ingestive priming occurs more slowly when there is a task switch (i.e., when ingestive activity is preceded by egestive activity).

We hypothesized that the outward current induced during egestive priming was at least partially responsible for the negative biasing that we observed during the task switch. To determine whether this was the case, we triggered ingestive priming under normal conditions (no current addition) (Fig. 10A, left) and in the situation where the outward current was artificially added using the dynamic clamp (Fig. 10A, right). We found that current addition had a significant effect (Fig. 10B; two-way repeated-measures ANOVA; $n=7 ; F_{(1,6)}=7.7, p=3.2 \times 10^{-2}$ ). With no current addition, the B8 firing frequency was $>4 \mathrm{~Hz}$ in the third cycle. When the current was added, the B8 firing was still $<4 \mathrm{~Hz}$ in the seventh cycle. In a second set of experiments, we used dynamic clamp techniques to subtract the outward current. Thus, we induced negative biasing under normal conditions (no subtraction; Fig. 11A, left) and with the outward current subtracted (Fig. 11A, right). Current subtraction had a significant effect (Fig. 11B; two-way ANOVA; $n=4$ for both negative biasing without current addition and with current addition; $F_{(1,41)}=$ 59.9, $\left.p<1.0 \times 10^{-4}\right)$. Together, these data indicate that induction of the outward current plays an important role during negative biasing.

\section{Discussion}

Network activity is often configured by modulatory neurotransmitters (Bargmann, 2012; Marder, 2012). One modulator (or set of modulators) produces one type of output, whereas a second set of modulators produces a second output. Further, modulators that produce different outputs are often released under different conditions. Consequently, in one set of circumstances, modulators are released that configure activity so that an output is generated that is appropriate at the time. When circumstances change, different modulators are released and a different output is generated. In this situation, a modulator is not expected to exert an effect that is "counterproductive" in the sense that it impedes, rather than promotes, the establishment of the configuration that is appropriate when release occurs. In this study, we identify a situation where this happens. Further, we present data that strongly suggest that a modulatory effect that is counterproductive when release occurs can play an anticipatory that is important when there is a task switch.

\section{An outward current is induced during egestive priming in the feeding network}

Our experiments were conducted in the feeding network in Aplysia, a system that undergoes repetition priming (Proekt et al., 2004; Friedman and Weiss, 2010; Cropper et al., 2014; Friedman et al., 2015; Siniscalchi et al., 2016). When a single cycle of motor activity is triggered by stimulating either an ingestive or egestive input to the feeding CPG, it has "intermediate" characteristics. Motor neurons fire at low frequencies and antagonists are coactive. With repeated input activation, however, phase definition occurs. With repeated stimulation of the EN (which contains processes of gut afferents) (Kuslansky et al., 1987), activity becomes egestive (Proekt et al., 2004; Zhurov et al., 2005; Friedman et al., 2015; Siniscalchi et al., 2016). This is manifested as progressive increases in the firing frequency of the B8 radula closer motor neurons during the radula protraction phase of the motor program. (Radula closing during protraction pushes food out.)

Previous studies that sought to determine why firing frequency increases during egestive repetition priming demonstrated that B8 receives increased synaptic input (Proekt et al., 2004, 2007; Wang et al., 2019). To a large extent, this input is from an interneuron, B20. The B20 firing frequency increases during egestive priming in part because peptides (the SCPs) are released when EN afferents are activated (Wu et al., 2010). The SCPs increase the excitability of B20, and increase the excitability of a second interneuron (B65) that provides excitatory drive to B20 (Wu et al., 2010). Finally, in addition to increases in B20 activity, SCP potentiates B20-B8 synaptic transmission (Wu et al., 2010).

Here we demonstrate that, in addition to the increase in synaptic drive, a persistent current is induced in B8 as egestive priming develops. This current is outward rather than inward. Our data indicate that it is to a large extent induced by a second family of peptides (the FRFamide peptides) that are released when the EN is stimulated (Vilim et al., 2010). Interestingly, the induction of the outward current is "counterproductive" during egestive priming because it decreases the B8 excitability. The B8 firing frequency increases anyway because there is such a large increase in synaptic drive. This leads to the question: why is the 

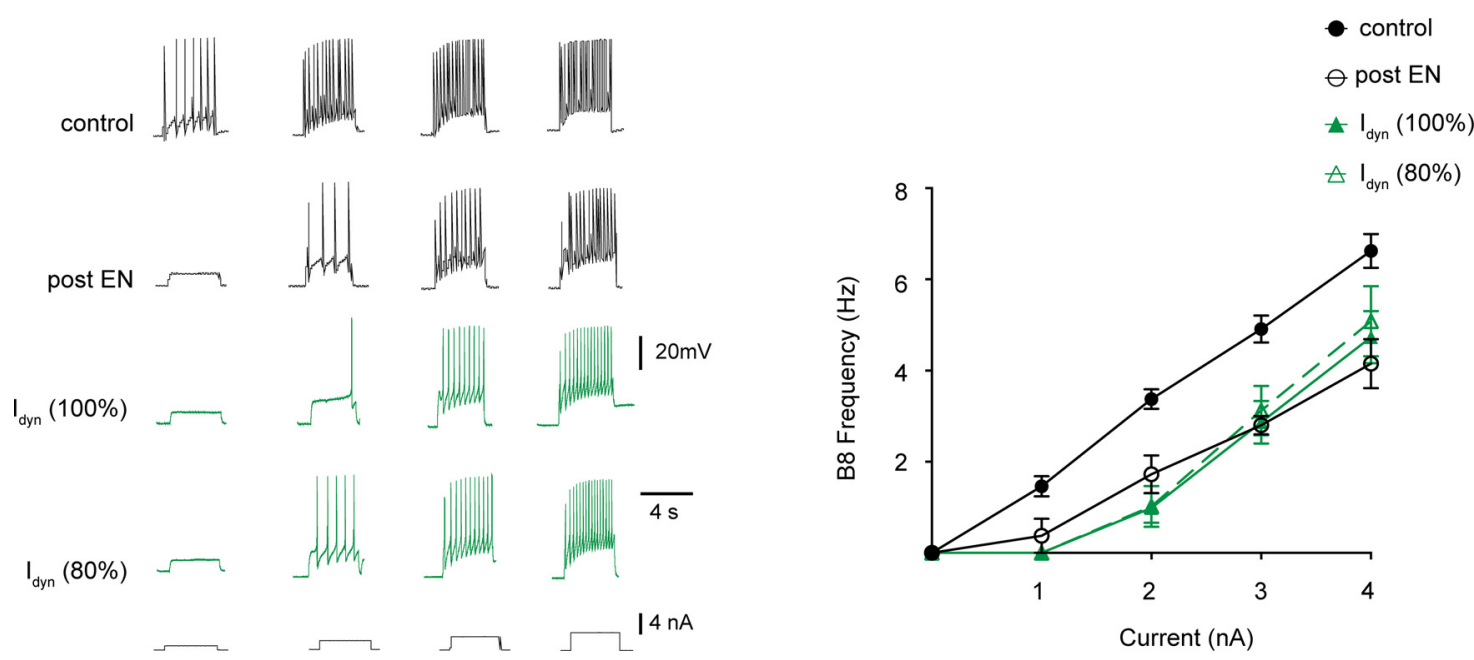

Figure 7. Dynamic clamp introduction of the outward current modifies the B8 current-frequency relationship. Left, Recordings after injection of $4 \mathrm{~s}$ constant current pulses of 1, 2, 3, and $4 \mathrm{nA}$. The resting membrane potential was $-63 \mathrm{mV}$ before current pulses were injected (control condition) and at the start of each dynamic clamp run. It was $-66 \mathrm{mV}$ after EN stimulation. Right, Recordings were obtained without artificial current injection (black traces and plots), before egestive priming (control; filled black circles; $n=10$ ) and $30 \mathrm{~s}$ after EN stimulation (open black circles; $n=4)$. Additionally, recordings were obtained when the outward current was artificially added using dynamic clamp techniques (green traces and plots). The current was added at $100 \% \mathrm{~g}_{\max }$ (filled green triangles; $n=5$ ) and at $80 \% \mathrm{~g}_{\max }$ (open green triangles; $n=5$ ). The $\mathrm{B} 8$ excitability was significantly decreased both by EN stimulation and dynamic clamp introduction of the outward current.

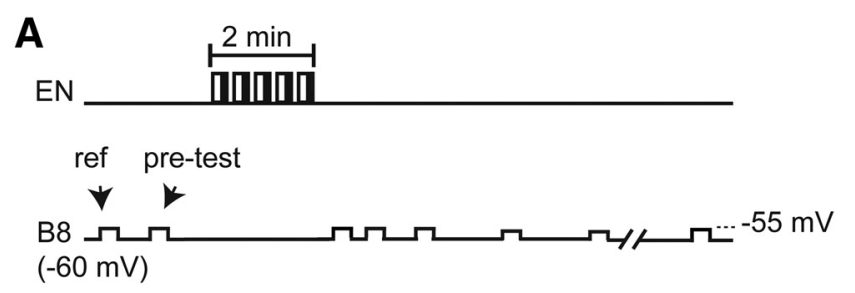

B

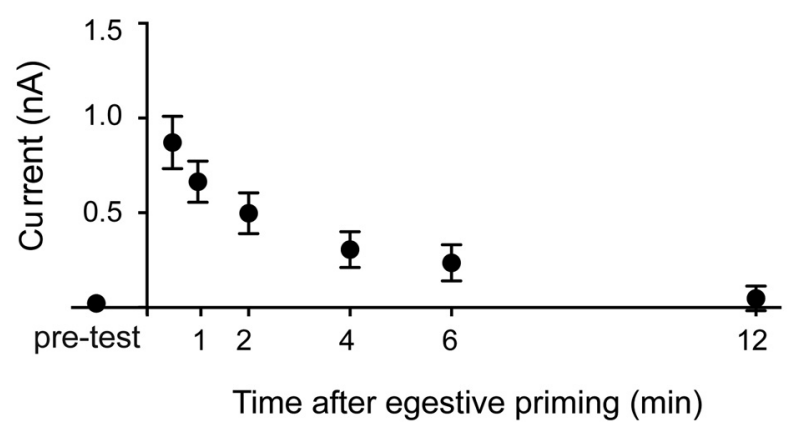

Figure 8. Persistence of the outward current. The outward current was measured by holding $B 8$ at its normal resting potential $(-60 \mathrm{mV})$ and stepping to $-55 \mathrm{mV}$ before (pretest) and at selected time points after $\mathrm{EN}$ stimulation $(\boldsymbol{A})$. Group data are shown in $(\boldsymbol{B})$. All pulses were subtracted from the same reference pulse delivered before the pretest (ref) $(n=9)$.

current induced? We show that the outward current persists for minutes. When Aplysia feed, they can switch from one type of behavior to another in this time frame (Nagahama and Shin, 1998; Proekt et al., 2008). Thus, the induction of the current could be important when there is a task switch.

\section{A role for the outward current during task switching}

The readiness with which task switching in the feeding network occurs depends on whether it is a switch from egestion to ingestion or a switch from ingestion to egestion (Proekt et al., 2004; Dacks and Weiss, 2013; Wang et al., 2019). Thus, task switching in Aplysia is asymmetrical as it is in other systems (Yeung and Monsell, 2003; Kiesel et al., 2010; Barutchu et al., 2013). In the egestion to ingestion direction, a "negative" bias has been reported (Proekt et al., 2004; Dacks and Weiss, 2013; Wang et al., 2019). In these studies, egestive repetition priming was induced by repeatedly stimulating the EN. Subsequently, a cycle of activity was triggered using CBI-2 (the ingestive input to the feeding CPG). This cycle of activity was egestive. Here we elaborate on this finding and demonstrate that it is not just a single cycle that is impacted by a prior bout of egestive priming. Effects of egestive priming persist, and last for minutes. Consequently, a series of several CBI-2-induced cycles of activity is impacted by a prior bout of egestive activity.

We show that negative biasing is manifested as depressed activity in the $\mathrm{B} 8$ radula closer motor neurons during the radula retraction phase of the motor program (Fig. 9). For example, when negative biasing is observed, the B8 firing frequency remains $<4 \mathrm{~Hz}$ for several cycles of activity. When $\mathrm{B} 8$ fires at this rate, there is virtually no measurable radula closing (Friedman et al., 2009). In principle, depressed B8 activity could result from either a reduction in excitability, and/or reduced synaptic input. Here we demonstrate that the persistent outward current that is induced during egestive priming produces an excitability decrease (Fig. 7). Further, we conduct dynamic clamp addition and subtraction experiments, which demonstrate that manipulation of the outward current significantly impacts the B8 firing frequency during motor activity (Figs. 10, 11). Together, these data strongly suggest that at least one function of the outward current is that it plays a role during negative biasing.

\section{Switches between ingestive and egestive behavior}

Relatively dynamic switching between feeding behaviors has been described in multiple species, including mammals (Dinardo and Travers, 1994). In molluscs, switches between egestive and ingestive activity apparently occur under more than one circumstance. For example, in a laboratory setting egestion can be induced by stretch of the esophagus (Croll and Davis, 1981, 1982). It has been suggested that in this situation a reflex has 
A

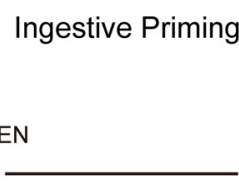

$\mathrm{CBI}-2$

पणमापवतणत

12345678910
Negative biasing

2 min

ппппппп

12345678910
B

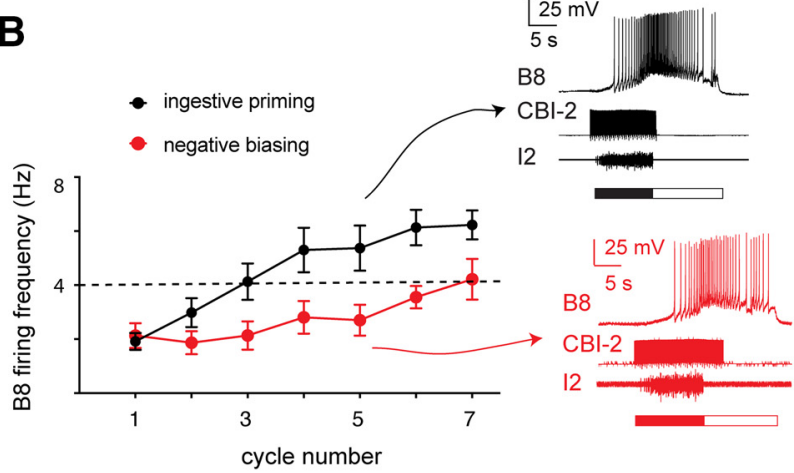

Figure 9. Egestive priming has a negative effect on subsequent ingestive priming. Ingestive priming was induced by repeated stimulation of (BI-2 so that cycles of activity were triggered every $30 \mathrm{~s}(\boldsymbol{A}$, left; $n=7)$. Preparations were rested, and then negative biasing was induced (i.e., ingestive priming was preceded by a previous bout of egestive priming) $(\boldsymbol{A}$, right; $n=7)$. $\boldsymbol{B}$, Plot of the B8 firing frequency during the radula closing phase of the motor program under both conditions. Red represents negative biasing data. Insets, Recordings from the fifth cycle of activity. Top two traces, Intracellular recordings from B8 and CBI-2. Bottom, Extracellular recording from the 12 nerve. Filled bar below the traces represents the radula protraction phase of the motor program. Open bar represents the radula retraction phase. Dashed line in the plot indicates the B8 frequency where functional closing is induced $(\sim 4 \mathrm{~Hz})$. Ingestive priming occurred more slowly after EN stimulation.

A

no current added

$\mathrm{CBI}-2$

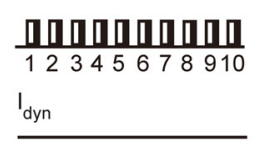

Ingestive Priming

outward current added

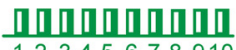

12345678910

पप口पप
B

Ingestive Priming

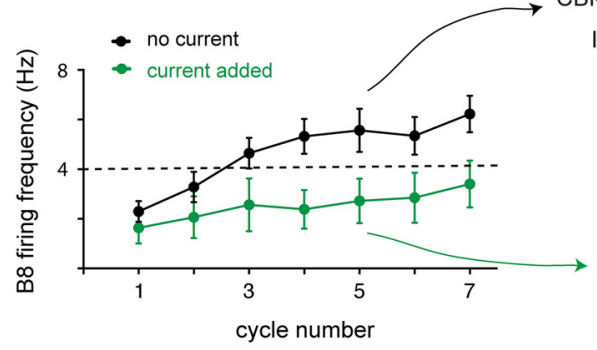

B8

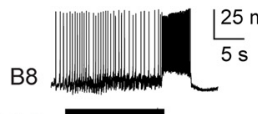

CBI-2

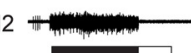

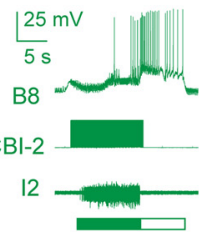

Figure 10. Dynamic clamp addition of the outward current mimics effects of negative biasing. Preparations were subjected to either ingestive priming without current addition $(\boldsymbol{A}$, left; $n=7)$ or ingestive priming with current addition $(\boldsymbol{A}$, right; $n=7)$. $\boldsymbol{B}$, Plot of the B8 firing frequency during the radula closing phase of the motor program under both conditions. Green represents data with the current added. Insets, Recordings from the fifth cycle of activity. Top two traces, Intracellular recordings from B8 and CBI-2. Bottom, Extracellular recording from the 12 nerve. Filled bar below the traces represents the radula protraction phase of the motor program. Open bar represents the radula retraction phase. Dashed line in the plot indicates the B8 frequency where functional closing is induced $(\sim 4 \mathrm{~Hz})$. Addition of the outward current slowed the rate at which ingestive priming occurred.

A

Negative Biasing

no current added
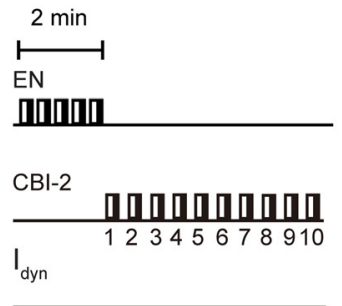

outward current subtracted



매매

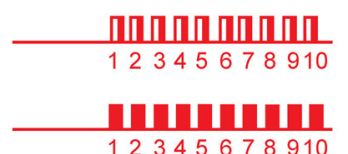

B

Negative Biasing
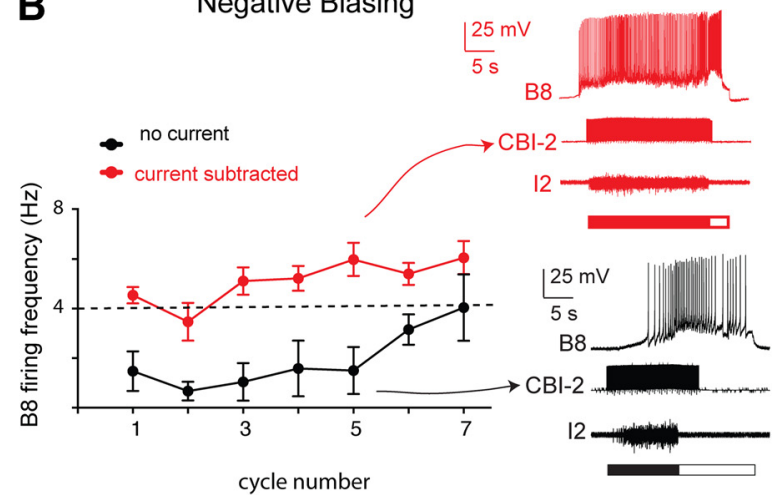

Figure 11. Dynamic clamp subtraction of the outward current alters the $B 8$ firing frequency during negative biasing. In some preparations, we induced negative biasing under normal conditions (no current subtraction; $\boldsymbol{A}$, left; $n=4)$ ). In other preparations, negative biasing was induced with dynamic clamp subtraction of the outward current $(\boldsymbol{A}$, right; $n=4)$. $\boldsymbol{B}$, Plot of the B8 firing frequency during the radula closing phase of the motor program under both conditions. Green represents data with the current subtracted. Insets, Recordings from the fifth cycle of activity. Top two traces, Intracellular recordings from B8 and CBI-2. Bottom, Extracellular recording from the I2 nerve. Filled bar below the traces represents the radula protraction phase of the motor program. Open bar represents the radula retraction phase. Dashed line in the plot indicates the B8 frequency where functional closing is induced ( $\sim \mathrm{Hz})$. Subtraction of the outward current had a significant effect. 
been triggered that is important under physiological conditions because it results in the expulsion of an object that cannot be injected (i.e., it "clears" the esophagus). In Aplysia, rejection is often triggered using a polyethylene tube (Kupfermann, 1974; Cropper et al., 1990; Morton and Chiel, 1993a; Horn and Kupfermann, 2002). The tube is either inserted, or pulled into the buccal cavity by the animal so that it acts as a postingestive stimulus. Clearing responses can presumably be triggered at any point during a meal. Additionally, when Aplysia feed continuously for a prolonged period of time, there is a progressive decrease in the fraction of ingestive responses, and a progressive increase in the number of egestive and intermediate responses (Jing et al., 2007). Presumably, this change represents a switch to a satiety state. In both types of circumstances, a negative effect of egestion on ingestion is presumably beneficial. It will either reduce the tendency to ingest something that is inedible and/or will contribute to satiation.

\section{Negative biasing as a preparatory state}

What we demonstrate is in some respects similar to the idea of a "preparatory" or anticipatory state. Previously described preparatory states differ, however, in that they most commonly promote a subsequent behavior or event. For example, in tasks where there is a delay period in between an instruction and go cue, the overall response to an expected stimulus is often improved (e.g., Rosenbaum, 1980; Riehle and Requin, 1993; Churchland et al., 2006; Michaels et al., 2015). In the feeding system of Aplysia, activity in the serotonergic metacerebral cells can decrease the latency of subsequent motor program initiation (Proekt and Weiss, 2003). Further, a previous bout of ingestive activity can promote a subsequent bout of egestion via a latent modulatory effect (Dacks and Weiss, 2013). The results of the present study differ in that we describe carryover of a "negative" effect. It is interesting to note that a recent computational report that studied learning induced changes in a model of the feeding network manipulated individual sites of plasticity to determine how each site impacted the establishment of an overall engram (Costa et al., 2020). Although most individual effects positively contributed to the establishment of the engram, one did not. Thus, "counterproductive" modifications of circuit parameters may be more common than is currently recognized.

In conclusion, we identify a persistent circuit modification (induction of an outward current) that does not immediately promote the establishment of a behaviorally appropriate network configuration. We ask why this occurs, and determine whether it could influence task switching. We present data that strongly support the idea that it does. In particular, our data suggest that the outward current plays an important role in the negative biasing that is seen when there is a transition from egestive to ingestive activity. In effect, induction of the outward current anticipates the transition. It is possible that the mechanism that we describe operates in other species and systems. A negative effect of egestion on subsequent ingestion is observed in many species.

\section{References}

Bargmann CI (2012) Beyond the connectome: how neuromodulators shape neural circuits. Bioessays 34:458-465.

Barutchu A, Becker SI, Carter O, Hester R, Levy NL (2013) The role of taskrelated learned representations in explaining asymmetries in task switching. PLoS One 8:e61729.

Brezina V, Bank B, Cropper EC, Rosen S, Vilim FS, Kupfermann I, Weiss KR (1995) Nine members of the myomodulin family of peptide cotransmitters at the B16-ARC neuromuscular junction of Aplysia. J Neurophysiol 74:54-72.

Church PJ, Lloyd PE (1994) Activity of multiple identified motor neurons recorded intracellularly during evoked feedinglike motor programs in Aplysia. J Neurophysiol 72:1794-1809.

Churchland MM, Yu BM, Ryu SI, Santhanam G, Shenoy KV (2006) Neural variability in premotor cortex provides a signature of motor preparation. J Neurosci 26:3697-3712.

Costa RM, Baxter DA, Byrne JH (2020) Computational model of the distributed representation of operant reward memory: combinatoric engagement of intrinsic and synaptic plasticity mechanisms. Learn Mem 27:236-249.

Croll RP, Davis WJ (1981) Motor program switching in pleurobranchaea: 1. Behavioral and electro-myographic study of ingestion and egestion in intact specimens. J Comp Physiol 145:277-287.

Croll RP, Davis WJ (1982) Motor program switching in pleurobranchaea: 2. Ingestion and egestion in the reduced preparation. J Comp Physiol 147:143-154.

Cropper EC, Kupfermann I, Weiss KR (1990) Differential firing patterns of the peptide-containing cholinergic motor neurons B15 and B16 during feeding behavior in Aplysia. Brain Res 522:176-179.

Cropper EC, Brezina V, Vilim FS, Harish O, Price DA, Rosen S, Kupfermann I, Weiss KR (1994) FRF peptides in the ARC neuromuscular system of Aplysia: purification and physiological actions. J Neurophysiol 72:21812195.

Cropper EC, Friedman AK, Jing J, Perkins MH, Weiss KR (2014) Neuromodulation as a mechanism for the induction of repetition priming. Curr Opin Neurobiol 29:33-38.

Cropper EC, Jing J, Perkins MH, Weiss KR (2017) Use of the Aplysia feeding network to study repetition priming of an episodic behavior. J Neurophysiol 118:1861-1870.

Dacks AM, Weiss KR (2013) Latent modulation: a basis for non-disruptive promotion of two incompatible behaviors by a single network state. J Neurosci 33:3786-3798.

Dinardo LA, Travers JB (1994) Hypoglossal neural activity during ingestion and rejection in the awake rat. J Neurophysiol 72:1181-1191.

Friedman AK, Weiss KR (2010) Repetition priming of motoneuronal activity in a small motor network: intercellular and intracellular signaling. J Neurosci 30:8906-8919.

Friedman AK, Weiss KR, Cropper EC (2015) Specificity of repetition priming: the role of chemical coding. J Neurosci 35:6326-6334.

Friedman AK, Zhurov Y, Ludwar B, Weiss KR (2009) Motor outputs in a multitasking network: relative contributions of inputs and experience-dependent network states. J Neurophysiol 102:3711-3727.

Furukawa Y, Nakamaru K, Wakayama H, Fujisawa Y, Minakata H, Ohta S, Morishita F, Matsushima O, Li L, Romanova E, Sweedler JV, Park JH, Romero A, Cropper EC, Dembrow NC, Jing J, Weiss KR, Vilim FS (2001) The enterins: a novel family of neuropeptides isolated from the enteric nervous system and CNS of Aplysia. J Neurosci 21:8247-8261.

Horn CC, Kupfermann I (2002) Egestive feeding responses in Aplysia persist after sectioning of the cerebral-buccal connectives: evidence for multiple sites of control of motor programs. Neurosci Lett 323:175-178.

Hurwitz I, Susswein AJ (1996) B64, a newly identified central pattern generator element producing a phase switch from protraction to retraction in buccal motor programs of Aplysia californica. J Neurophysiol 75:13271344.

Hurwitz I, Perrins R, Xin Y, Weiss KR, Kupfermann I (1999) C-PR neuron of Aplysia has differential effects on 'Feeding' cerebral interneurons, including myomodulin-positive CBI-12. J Neurophysiol 81:521-534.

Jing J, Weiss KR (2001) Neural mechanisms of motor program switching in Aplysia. J Neurosci 21:7349-7362.

Jing J, Weiss KR (2002) Interneuronal basis of the generation of related but distinct motor programs in Aplysia: implications for current neuronal models of vertebrate intralimb coordination. J Neurosci 22:6228-6238.

Jing J, Cropper EC, Hurwitz I, Weiss KR (2004) The construction of movement with behavior-specific and behavior-independent modules. J Neurosci 24:6315-6325.

Jing J, Vilim FS, Horn CC, Alexeeva V, Hatcher NG, Sasaki K, Yashina I, Zhurov Y, Kupfermann I, Sweedler JV, Weiss KR (2007) From hunger to satiety: reconfiguration of a feeding network by Aplysia neuropeptide Y. J Neurosci 27:3490-3502 
Jing J, Sweedler JV, Cropper EC, Alexeeva V, Park JH, Romanova EV, Xie F, Dembrow NC, Ludwar BC, Weiss KR, Vilim FS (2010) Feedforward compensation mediated by the central and peripheral actions of a single neuropeptide discovered using representational difference analysis. J Neurosci 30:16545-16558.

Kiesel A, Steinhauser M, Wendt M, Falkenstein M, Jost K, Philipp AM, Koch I (2010) Control and interference in task switching: a review. Psychol Bull 136:849-874.

Krings W, Faust T, Kovalev A, Neiber MT, Glaubrecht M, Gorb S (2019) In slow motion: radula motion pattern and forces exerted to the substrate in the land snail Cornu aspersum (Mollusca, Gastropoda) during feeding. R Soc Open Sci 6:190222.

Kupfermann I (1974) Feeding behavior in Aplysia: a simple system for the study of motivation. Behav Biol 10:1-26.

Kuslansky B, Weiss KR, Kupfermann I (1987) Mechanisms underlying satiation of feeding-behavior of the mollusk Aplysia. Behav Neural Biol 48:278-303.

Lloyd PE, Kupfermann I, Weiss KR (1988) Central peptidergic neurons regulate gut motility in Aplysia. J Neurophysiol 59:1613-1626.

Mahon AC, Lloyd PE, Weiss KR, Kupfermann I, Scheller RH (1985) The small cardioactive peptides A and B of Aplysia are derived from a common precursor molecule. Proc Natl Acad Sci USA 82:3925-3929.

Marder E (2012) Neuromodulation of neuronal circuits: back to the future. Neuron 76:1-11.

Michaels JA, Dann B, Intveld RW, Scherberger H (2015) Predicting reaction time from the neural state space of the premotor and parietal grasping network. J Neurosci 35:11415-11432.

Morgan PT, Perrins R, Lloyd PE, Weiss KR (2000) Intrinsic and extrinsic modulation of a single central pattern generating circuit. J Neurophysiol 84:1186-1193.

Morgan PT, Jing J, Vilim FS, Weiss KR (2002) Interneuronal and peptidergic control of motor pattern switching in Aplysia. J Neurophysiol 87:49-61.

Morton DW, Chiel HJ (1993a) In vivo buccal nerve activity that distinguishes ingestion from rejection can be used to predict behavioral transitions in Aplysia. J Comp Physiol A 172:17-32.

Morton DW, Chiel HJ (1993b) The timing of activity in motor neurons that produce radula movements distinguishes ingestion from rejection in Aplysia. J Comp Physiol A 173:519-536.

Nagahama T, Shin N (1998) Patterned jaw movements and the motor neuron activity during rejection of seaweed in Aplysia kurodai. J Comp Physiol A 182:551-562.

Nargeot R, Baxter DA, Byrne JH (1999) In vitro analog of operant conditioning in Aplysia: II. Modifications of the functional dynamics of an identified neuron contribute to motor pattern selection. J Neurosci 19:22612272.

Perkins MH, Cropper EC, Weiss KR (2018) Cellular effects of repetition priming in the Aplysia feeding network are suppressed during a task-switch but persist and facilitate a return to the primed state. J Neurosci 38:64756490.

Proekt A, Weiss KR (2003) Convergent mechanisms mediate preparatory states and repetition priming in the feeding network of Aplysia. J Neurosci 23:4029-4033.

Proekt A, Brezina V, Weiss KR (2004) Dynamical basis of intentions and expectations in a simple neuronal network. Proc Natl Acad Sci USA 101:9447-9452.

Proekt A, Jing J, Weiss KR (2007) Multiple contributions of an input-representing neuron to the dynamics of the Aplysia feeding network. J Neurophysiol 97:3046-3056.

Proekt A, Wong J, Zhurov Y, Kozlova N, Weiss KR, Brezina V (2008) Predicting adaptive behavior in the environment from central nervous system dynamics. PLoS One 3:e3678.

Riehle A, Requin J (1993) The predictive value for performance speed of preparatory changes in neuronal activity of the monkey motor and premotor cortex. Behav Brain Res 53:35-49.

Root CM, Ko KI, Jafari A, Wang JW (2011) Presynaptic facilitation by neuropeptide signaling mediates odor-driven food search. Cell 145:133-144.

Rosen SC, Teyke T, Miller MW, Weiss KR, Kupfermann I (1991) Identification and characterization of cerebral-to-buccal interneurons implicated in the control of motor programs associated with feeding in Aplysia. J Neurosci 11:3630-3655.

Rosenbaum DA (1980) Human movement initiation: specification of arm, direction, and extent. J Exp Psychol Gen 109:444-474.

Sanchez JA, Kirk MD (2001) Cerebral-buccal pathways in Aplysia californica: synaptic connections, cooperative interneuronal effects and feedback during buccal motor programs. J Comp Physiol A 187:801-815.

Siniscalchi MJ, Cropper EC, Jing J, Weiss KR (2016) Repetition priming of motor activity mediated by a central pattern generator: the importance of extrinsic vs. intrinsic program initiators. J Neurophysiol 116:1821-1830.

Vilim FS, Sasaki K, Rybak J, Alexeeva V, Cropper EC, Jing J, Orekhova IV, Brezina V, Price D, Romanova EV, Rubakhin SS, Hatcher N, Sweedler JV, Weiss KR (2010) Distinct mechanisms produce functionally complementary actions of neuropeptides that are structurally related but derived from different precursors. J Neurosci 30:131-147.

Wang Y, Weiss KR, Cropper EC (2019) Network degeneracy and the dynamics of task switching in the feeding circuit in Aplysia. J Neurosci 39:87058716.

Wu JS, Vilim FS, Hatcher NG, Due MR, Sweedler JV, Weiss KR, Jing J (2010) Composite modulatory feedforward loop contributes to the establishment of a network state. J Neurophysiol 103:2174-2184.

Yeung N, Monsell S (2003) Switching between tasks of unequal familiarity: the role of stimulus-attribute and response-set selection. J Exp Psychol Hum Percept Perform 29:455-469.

Zhurov Y, Proekt A, Weiss KR, Brezina V (2005) Changes of internal state are expressed in coherent shifts of neuromuscular activity in Aplysia feeding behavior. J Neurosci 25:1268-1280. 